\title{
Influencing the decline of lung function in COPD: use of pharmacotherapy
}

This article was published in the following Dove Press journal:

International Journal of COPD

15 May 2010

Number of times this article has been viewed

\author{
Ekaterina S Gladysheva' \\ Atul Malhotra ${ }^{2}$ \\ Robert L Owens ${ }^{2}$ \\ 'Harvard Combined Pulmonary and \\ Critical Care Fellowship, Harvard \\ Medical School, Boston, MA, USA; \\ 2Pulmonary and Critical Care and \\ Sleep Divisions, Brigham and Women's \\ Hospital, MA, USA
}

Correspondence: Robert L Owens Clinical and Research Fellow, Pulmonary and Critical Care and Sleep Divisions, Brigham and Women's Hospital,

22I Longwood Avenue, Boston,

MA 02115 , USA

$\mathrm{Tel}+\mathrm{I}(617) 525-87 \mathrm{II}$

Fax +I (6I7) 732-7337

Email rowens@partners.org

\begin{abstract}
Chronic obstructive pulmonary disease (COPD) is a common and deadly disease. One of the hallmarks of COPD is an accelerated decline in lung function, as measured by spirometry. Inflammation, oxidative stress and other pathways are hypothesized to be important in this deterioration. Because progressive airflow obstruction is associated with considerable morbidity and mortality, a major goal of COPD treatment has been to slow or prevent the accelerated decline in lung function. Until recently, the only known effective intervention was smoking cessation. However, newly reported large clinical trials have shown that commonly used medications may help slow the rate of lung function decline. The effect of these medications is modest (and thus required such large, expensive trials) and to be of clinical benefit, therapy would likely need to start early in the course of disease and be prolonged. Such a treatment strategy aimed at preservation of lung function would need to be balanced against the side effects and costs of prolonged therapy. A variety of newer classes of medications may help target other pathophysiologically important pathways, and could be used in the future to prevent lung function decline in COPD.
\end{abstract}

Keywords: COPD, emphysema, pulmonary function, beta-agonist, anti-inflammatory, pharmacotherapy in COPD

\section{Introduction}

Chronic obstructive pulmonary disease (COPD) is a deadly and costly disease, both in the United States and around the world. Approximately 20 million Americans are affected, and there is likely a similar worldwide prevalence. COPD is increasingly recognized as a systemic disease with extra-pulmonary manifestations such as skeletal muscle myopathy, osteoporosis, anemia, and depression. ${ }^{1-3}$ It is also linked with cardiovascular co-morbidities and various malignancies. ${ }^{4,5}$ As a result, COPD is associated with major morbidity and mortality. In the United States, COPD is the fourth leading cause of death (behind heart disease, cancer and stroke) accounting for more than 119,000 deaths per year; however, the number of deaths due to COPD is increasing while most others causes decline. ${ }^{6}$ Furthermore, the prevalence and mortality of COPD has been increasing faster over the last two decades in women compared to men, so that mortality due to COPD is now equal among men and women. Thus, COPD is projected to overtake stroke as the third most common cause of death in the US by 2020. The estimated direct cost of COPD in the US is substantial, and a portion of this money is spent toward medications designed not only to alleviate symptoms, but also ideally to slow disease progression and reduce mortality. By 2012, COPD drug costs are expected to reach almost 6 billion dollars per year in the US, Japan, and part of Western Europe alone. ${ }^{7}$ This estimate excludes many large 
and populous areas, such as India and China, where COPD is becoming an increasingly recognized and prevalent condition, both due to smoking and other sources of air pollution., ${ }^{8,9}$

While greater emphasis is now placed on extra-pulmonary disease, the definition of COPD still rests upon airflow obstruction. Airflow obstruction, usually measured using spirometry, is a useful marker of disease since testing is reasonably reproducible and widely available. The Global Initiative for Chronic Obstructive Lung disease (GOLD) has proposed spirometric criteria for diagnosis and severity assessment of COPD using the forced expiratory volume in one second $\left(\mathrm{FEV}_{1}\right)$ and the ratio of the $\mathrm{FEV}_{1}$ over the forced vital capacity (FVC) after bronchodilator. ${ }^{10}$ When incorporated with other clinical information, spirometry can also be used to predict survival in COPD. ${ }^{11}$ Progression of airflow obstruction, another hallmark of COPD, can also be determined by serial spirometry measurements over time. Sustained improvements in spirometry, or at least a reduction in the rate of $\mathrm{FEV}_{1}$ decline, should reflect reduced morbidity and mortality.

Until recently, the only known intervention to slow disease progression was cigarette smoking cessation. ${ }^{12,13}$ However, greater understanding of disease pathogenesis has provided new targets for intervention. Furthermore, large clinical trials have recently been reported in the literature to help assess whether commonly used medications slow disease progression. This review will focus on COPD pathogenesis, review recent clinical trial results, and highlight other potential therapeutic options.

\section{Normal lung function, aging, and smoking}

Lung function has traditionally been measured using pulmonary function tests, particularly spirometry. However, spirometry is actually a measurement of a number of physical and mechanical properties of the respiratory system, including resistance of the airways, elasticity of the respiratory system, and contractile forces of the respiratory muscles. True lung function may also require assessment of arterial oxygen or carbon dioxide tension, but spirometry has the advantages of being non-invasive, standardized, and reproducible. Normative data are also available, allowing appropriate matching for differences in sex, height, race and age. Thus, pulmonary function tests are frequently used for diagnosis, assessment of disease severity, disease progression, response to treatment, and for prognosis in a variety of respiratory disorders.
Consideration of age is necessary given the myriad changes that occur in the respiratory system even with normal aging. With aging, there are changes not only in lung parenchyma but also in chest wall shape and in muscle forces - all of which affect spirometry. While the exact shape and details of the curve describing lung function (as assessed by $\mathrm{FEV}_{1}$ ) by age has yet to be determined, the general shape is shown in Figure 1. As might be expected, $\mathrm{FEV}_{1}$ rapidly increases during childhood and adolescence, before reaching a plateau in early adulthood. ${ }^{14,15}$ Interestingly, the peak of lung function appears to occur after maximum height has been achieved, so that the improvements in spirometry are not just due to increased lung size (and thus airway caliber). Lung function remains stable at this plateau (with men having a higher plateau value than women) until approximately age 25 to 30 years, after which $\mathrm{FEV}_{1}$ slowly declines. Although there is some controversy as to whether the decline in $\mathrm{FEV}_{1}$ is linear with age or accelerates with aging, ${ }^{16}$ some of the most robust data suggest that lung function decreases approximately $20 \mathrm{~mL}$ per year during middle age, and then decreases more rapidly by about $38 \mathrm{~mL}$ per year after age $65 .{ }^{17,18}$

Regardless of the exact rate of decline in $\mathrm{FEV}_{1}$ with age, the decline is likely due to a combination of age-related changes of the parenchyma, the chest wall, and the respiratory muscles, which may be difficult to separate using spirometry alone. The chest wall may change with aging due to reduced height of thoracic vertebrae, or stiffening or calcification of the costal joints of the rib cage. Direct measurements have confirmed decreased compliance of the

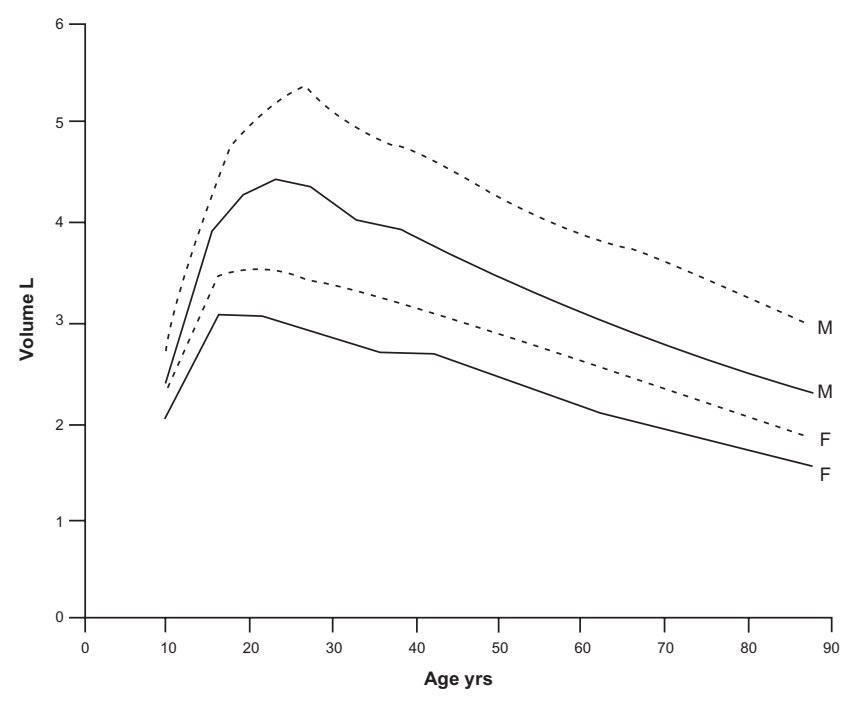

Figure I Normal changes in FEV, (solid line) and FVC (dashed line) for men (M) and women (F). Reproduced with permission from Janssens JP, Pache JC, Nicod LP. Physiological changes in respiratory function associated with ageing. Eur Respir J. 1999; 13(1):197-205. ${ }^{14}$ Copyright (C) 1999 European Respiratory Journals Ltd. 
chest wall with aging. ${ }^{19,20}$ Respiratory muscle function also changes with age. Studies of diaphragm strength have shown a $13 \%$ to $25 \%$ drop in the maximal inspiratory force generated with aging. ${ }^{21,22}$ In general, skeletal muscle function, which predicts maximal inspiratory and expiratory pressure (MIP and MEP), also decreases with age. ${ }^{23,24}$ Taken together, these changes may limit the maximal inspiratory and expiratory effort that contribute to $\mathrm{FEV}_{1}$. Perhaps most important in explaining the age-related decline are changes in the lung parenchyma. Pathological studies have shown that beyond age 50 years, elastic fibers at the level of the respiratory bronchiole and alveolus degenerate, or rupture and appear coiled - although the total number of alveolar connections remains unchanged (in contrast to emphysema induced by cigarette smoking). ${ }^{25,26}$ The abnormal and presumably weakened connections lead to uniform airspace dilatation, a condition that Verbeken and colleagues called "senile emphysema." The functional result of these parenchymal lung changes are a decrease in the elastic recoil pressure of the lung and a weakening of the supporting structures of the small airways, which more easily close, even during tidal breathing. ${ }^{27-29}$ All of these changes contribute to the gradual decline in $\mathrm{FEV}_{1}$ with increasing age.

The changes in lung parenchyma (decreased elastic recoil), chest wall (increased stiffness), and the respiratory muscles (decreased force generation) explain the observed changes in lung volume with aging. Total lung capacity remains relatively preserved since the increased distensibility of the lung is offset by the stiffer chest wall. Residual volume (RV) and functional residual capacity (FRC) both increase, but expiratory reserve volume (ERV) decreases. ${ }^{30,31}$

\section{Changes in lung function with smoking and COPD}

Smoking impacts all phases of lung development and growth, and can limit the maximal lung function attained, ${ }^{32,33}$ shorten the duration of the plateau phase prior to the decline with aging, ${ }^{34}$ and accelerate the decline in lung function. ${ }^{13}$ Although the precise numbers may vary slightly in other studies, ${ }^{35,36}$ the findings of Fletcher and Peto encapsulate the known consequences of smoking on lung function decline (see Figure 2). ${ }^{13}$ First, smokers show an accelerated rate of decline in $\mathrm{FEV}_{1}$ compared to those who have never smoked; an average loss of approximately $50 \mathrm{~mL}$ per year. Of note, while this rate may be approximately double the normal rate of decline, this small absolute change per year could be difficult to detect in short trials. Second, on average there is a dose-dependent loss in lung function: in general, greater

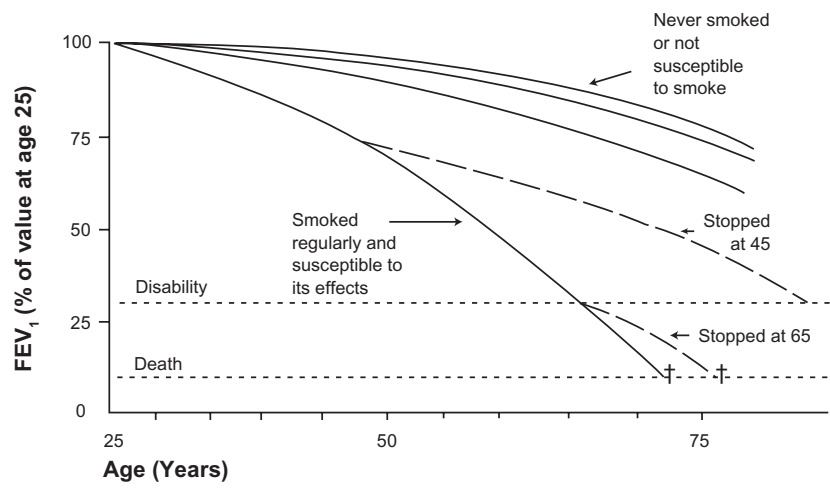

Figure 2 The decline in lung function with age, smoking, and smoking cessation. Note that the decline in lung function among "susceptible" smokers will be variable. Reproduced with permission from Fletcher C, Peto R. The natural history of chronic airflow obstruction. Br Med J. 1977; I(6077): 1645-1648. ${ }^{13}$ Copyright (C) 1977 British Medical Association.

amounts of smoking lead to greater declines in $\mathrm{FEV}_{1}$. Third, there is variable susceptibility to the effects of smoking. That is, for a given amount of smoking, there is a variable rate of decline in lung function among different subjects, presumably reflecting genetic ${ }^{37}$ or other environmental factors, although the rate of decline appears to be similar between men and women. ${ }^{35,38}$ Studies of lung function decline must be interpreted in terms of this "Horse Racing Effect" - the observation that in a race, the faster horse will be out in front in the middle of the race. In the context of smoking and lung function decline, subjects with evident lung function loss and clinical COPD are likely those with the fastest loss of lung function. Conversely, most smokers will not develop clinically significant COPD. ${ }^{39}$ Finally, the rate of lung function decline will slow, and may return to normal with smoking cessation. Whether the diagnosis of COPD by itself (ie, after smoking cessation) causes more rapid decline in lung function is unknown, and is difficult to decipher from the effects of smoking unless there is adequate follow-up time, typically several years..$^{40}$ Airway inflammation continues to persist for many years after smoking cessation, and improvements in hospitalization are not generally seen until years after smoking cessation. ${ }^{12,41}$ Therefore definitive data regarding COPD alone without smoking are difficult to obtain.

\section{Pathogenesis and pathology of COPD}

Knowledge about the pathogenesis of COPD will be helpful in understanding the causes of and ultimately treating the accelerated lung function decline. COPD is now recognized as a systemic inflammatory disease, not just affecting the airways and lung parenchyma, but many other organs as well. The 
GOLD definition emphasizes that the disease has systemic effects due to abnormal inflammation, defining COPD as:

"a preventable and treatable disease with some significant extra-pulmonary effects that may contribute to the severity in individual patients. Its pulmonary component is characterized by airflow limitation that is not fully reversible. The airflow limitation is usually progressive and associated with an abnormal inflammatory response of the lung to noxious particles or gases. ${ }^{10}$

Two patterns of airflow obstruction are commonly described, which can overlap in individual patients. An obstructive bronchiolitis can result from structural changes and narrowing of small airways. Parenchymal destruction leads to emphysema, with loss of supporting structures around the airways. The loss of elastic recoil promotes airway collapse during exhalation.

\section{Inflammation, oxidation, and premature aging}

The abnormal inflammatory response that causes these patterns of injury has yet to be fully characterized, and there are likely multiple pathways that lead to impaired lung function. Three major proposed mechanisms are: activation of elastolytic proteases, chronic oxidative stress, and accelerated aging. ${ }^{42-44}$ Cigarette smoking provides the initial stimulus which recruits cells into the lung parenchyma. Circulating monocytes become macrophages in the lung and subsequently recruit additional macrophages, neutrophils, and activated T-lymphocytes. The level of inflammation in COPD lungs is greater than that seen in the lungs of smokers without COPD, and the number of neutrophils in sputum is predictive of lung function decline. ${ }^{45}$ Unlike asthma, the inflammation with COPD is generally resistant to the effects of corticosteroids, and these pathological changes are progressive. Once activated, the recruited cells release enzymes such as neutrophil elastase and matrix metalloproteinase-9 (MMP-9) which destroy normal lung tissue. One of the hallmarks of COPD is this imbalance between proteases, which are part of the normal host defense to bacteria or foreign bodies, and inactivating anti-proteases; ${ }^{46}$ the subset of patients with genetic deficits in alpha-1 antitrypsin, a protease inhibitor, are a good example of this principle. One other clinical observation that suggests protease/anti-protease imbalance is the loss of skin elasticity and wrinkling that also occurs in and correlates with severity of emphysema; this also illustrates the extra-pulmonary effects of COPD, although such changes could also be the direct result of smoking. ${ }^{47}$ Oxidative stress may also play a role, either as a result of oxidants present in cigarette smoke or the generation and release of reactive oxygen species from leukocytes. Oxidative stress can increase activity of proteases, and lead to inactivation of anti-proteases. Finally, the changes seen with COPD may be an accelerated version of "senile emphysema." As described above, some of the same pathological changes seen with COPD also occur in elderly subjects, such as loss of elastic tissue and distal airspace enlargement. Several in vitro and animal studies support this hypothesis. For example, fibroblasts from those with emphysema have reduced proliferative capacity compared to control smokers, ${ }^{48}$ which may be related to telomere length. Telomere shortening is accelerated by oxidative stress and chronic inflammation. Additionally, the anti-aging molecule sirtuin SIRT1 is also reduced in murine COPD lungs. These and other changes suggest COPD could be a disease of premature aging. ${ }^{49}$

The inflammation that begins in the lung causes increased levels of a number of cytokines, chemokines and acute phase reactants. Whether these findings reflect "spill-over" of pulmonary inflammation, or a separate activation of a generalized inflammatory response, is unknown. ${ }^{3}$ Those with COPD have higher circulating levels of cytokines and acute phase reactants than those who smoke but do not have COPD. Interleukin-6, tumor necrosis factor alpha (TNF- $\alpha$ ), interleukin-8, and ghrelin are all elevated in COPD, as are C-reactive protein and fibrinogen. ${ }^{3}$ Although the effects of these substances are wide ranging, they probably modulate some of the systemic effects of COPD. For example, circulating IL-6 has been associated with skeletal muscle atrophy, and TNF- $\alpha$ with muscle atrophy and cachexia. These systemic effects could also contribute to decrements in spirometry. Thus, all of the pathways mentioned above represent potential targets for therapy.

\section{Exacerbations}

Exacerbations of COPD also appear to play a role in lung function decline. Although the definition is imprecise (and sometimes controversial), exacerbations are usually defined clinically by worsening symptoms, and are often associated with worsening pulmonary function and increased local and systemic inflammation. ${ }^{50}$ Those with frequent exacerbations appear to have more rapid decline in lung function and increased mortality (see Figure 3). ${ }^{51-53}$ Airway infection due to a variety of bacterial and/or viral pathogens is the most likely cause of exacerbations. ${ }^{54,55}$ Environmental exposures such as air pollution may also play a role, however, in up to one third of cases, no clear precipitant for the exacerbation can be identified. ${ }^{10}$ Because 


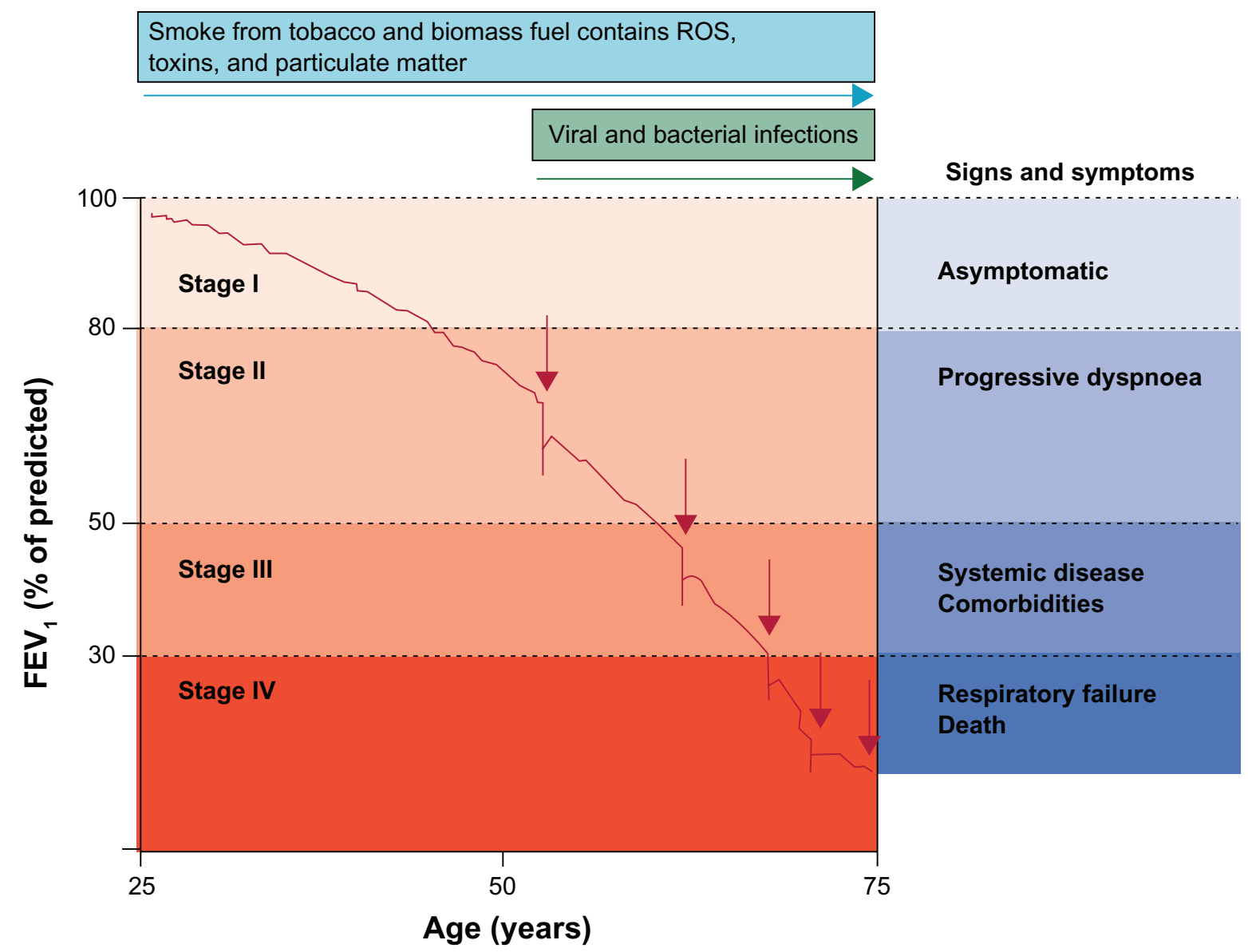

Figure 3 The role of exacerbations in accelerating lung function decline. Exacerbations (indicated by red arrows) punctuate and hasten lung function decline. Hansel TT, Barnes PJ. New drugs for exacerbations of chronic obstructive pulmonary disease. Lancet. 2009;374(969I):744-755.83 Copyright (C) 2009 Elsevier.

the same bacteria can be recovered from the lungs of COPD patients both before and during an exacerbation, bacterial infection was often dismissed as a cause for exacerbation. However, Sethi and colleagues found that exacerbations were associated with changes in the specific bacterial strain, suggesting that exacerbations can follow the acquisition of new pathological strains. Pathogens may more easily cause infection in the COPD lung, in which several normal defense mechanisms of innate immunity are impaired. For example, mucociliary function, alveolar macrophage phagocytosis and toll-like receptor expression are all impaired in COPD. ${ }^{56}$

\section{A rational approach to slow lung function decline}

Based on our current understanding of COPD pathogenesis outlined above, there are several targets for intervention. These include excessive inflammation, proteolysis, oxidative stress, and bacterial and viral infections that may trigger exacerbations.

\section{Commonly used COPD medications}

\section{Bronchodilators}

There are two commonly used classes of bronchodilators: beta-agonists and anti-cholinergics. Beta-agonists stimulate $\beta$-2 adrenergic receptors, increase levels of cyclic AMP, and thereby inhibit bronchoconstriction. Inhaled forms are preferred because of rapid onset of action and favorable side effect profile compared to the oral form. Short-acting inhaled beta-agonists, such as albuterol, salbutamol and levalbuterol, have a rapid onset of action (within minutes) and a duration of action on the order of 4 to 6 hours. Long-acting compounds such as salmeterol (onset of action up to one hour) and formoterol (onset of action within minutes) have a duration of action of approximately 12 hours without demonstrable tachyphylaxis with regular use. ${ }^{57}$ Anticholinergics block muscarinic receptors (M1, M2, and M3), blocking the action of acetylcholine on the airway smooth muscle, which leads to airway smooth muscle relaxation. Short-acting anticholinergic preparations 
(ipratropium, oxytropium) can have effects lasting up to 8 hours following administration, while the long-acting preparation (tiotropium) has effects that last more than 24 hours. Inhaled anticholinergic compounds have very limited systemic absorption.

By their effects on smooth muscle, bronchodilators can acutely improve lung function, hyperinflation, dyspnea, exercise tolerance and lessen the degree of nocturnal hypoxemia. ${ }^{58,59}$ Bronchodilator medications may also have other clinically relevant effects. For example, beta-agonists have effects on multiple components of the respiratory system, including: decreased airway smooth muscle proliferation; decreased neutrophil number, activity and function; and increased ciliary beat frequency. ${ }^{60}$ Some or all of these changes could help counteract excessive inflammation, restore innate immunity, or prevent airway remodeling. Similarly, the anti-cholinergic tiotropium has been shown to decrease respiratory syncytial virus replication (RSV) in an in vitro model, and decrease lung fibroblast collagen synthesis. ${ }^{61,62}$ Thus, these commonly used bronchodilators may affect the progression of COPD through pathways unrelated to their direct effects on bronchomotor tone.

\section{Corticosteroids}

Inhaled corticosteroids are frequently used in severe COPD to interrupt inflammatory pathways, although the effect on disease is less notable than the use of these medications in asthma. At least in moderate to severe COPD, inhaled corticosteroids can decrease the number of exacerbations and improve quality of life. ${ }^{63}$ Unfortunately, several small to moderate sized trials using inhaled corticosteroids failed to show a consistent effect of these medications on the rate of decline in $\mathrm{FEV}_{1}{ }^{63-66}$ For example, the Lung Health Research Study Group randomized more than 1100 subjects with all stages of COPD to the inhaled corticosteroid triamcinolone for 40 months: no difference was seen in the rate of lung function decline, the study's primary outcome. ${ }^{64}$ In the ISOLDE trial, 750 patients were randomized to inhaled fluticasone vs placebo for three years. The annual rate of decline in $\mathrm{FEV}_{1}$ was $50 \mathrm{~mL} /$ year in the fluticasone group and $59 \mathrm{~mL} /$ year in the placebo group, although the difference did not reach statistical significance $(P=0.16) .{ }^{63}$ A third contemporary trial by Pauwels and colleagues randomized over 1200 patients to budesonide or placebo for 3 years, and again, the rate of decline was not statistically significantly different $(P=0.39)$ between budesonide (-57 $\mathrm{mL} /$ year) vs placebo (-69 $\mathrm{mL} /$ year). A subgroup analysis suggested that the therapy was more effective in those who had less cigarette pack-year exposure. These studies and others have been combined via meta-analyses which reached conflicting conclusions about the efficacy of inhaled corticosteroids in ameliorating the decline in lung function. ${ }^{67,68}$ In the positive meta-analysis by Sutherland and colleagues, corticosteroids were found to reduce the rate of $\mathrm{FEV}_{1}$ decline by $7.7 \mathrm{~mL}$ per year compared to placebo. These moderate size trials illustrate the difficulty in detecting the difference in the rate of lung function decline between those patients with COPD not on treatment (with a reported $\mathrm{FEV}_{1}$ decline of $50 \mathrm{~mL}$ per year) and those patients with COPD on treatment (expected FEV decline $_{1}$ somewhere between 25 and $50 \mathrm{~mL}$ per year). Such small differences in lung function decline per year make it difficult to discern whether treatment with inhaled corticosteroids truly does alter lung function decline. Trials with both longer periods of active treatment and follow-up will be required to better answer this question. In aggregate, the existing data support a relatively small effect of inhaled steroids on $\mathrm{FEV}_{1}$ decline in COPD.

\section{TORCH and UPLIFT}

Two recent very large trials have examined the impact of these commonly used medications on the decline in $\mathrm{FEV}_{1}$. These trials are fundamentally different from prior work due to their large sample size and extended follow-up. The first results reported were from the Toward a Revolution in COPD Health (TORCH) study ${ }^{69}$ This was a multi-center, randomized, double-blind trial comparing treatment in moderate to severe COPD with placebo, salmeterol, fluticasone, or the combination of salmeterol and fluticasone. All cause mortality was the primary endpoint, although spirometry and rate of lung function decline was also assessed. Over 6000 patients were randomized, with about $60 \%$ of subjects completing the 3 -year trial. Overall, the combination therapy tended $(P=0.052)$ to improve absolute all-cause mortality by about $2.5 \%$.

A post-hoc analysis, done before treatment unblinding, was performed to assess the rate of decline in $\mathrm{FEV}_{1}$ (see Figure 4). ${ }^{38}$ In this group of former smokers, the change in post-bronchodilator $\mathrm{FEV}_{1}$ was $55 \mathrm{~mL}$ per year - similar to prior reported values. Treatment with either fluticasone or salmeterol was associated with a decline in $\mathrm{FEV}_{1}$ of only $42 \mathrm{~mL}$ per year; and the combination of drugs was $39 \mathrm{~mL}$ per year (not statistically significantly different from the individual drug components). There are some legitimate critiques of the trial. Specifically, dropouts were not randomly 


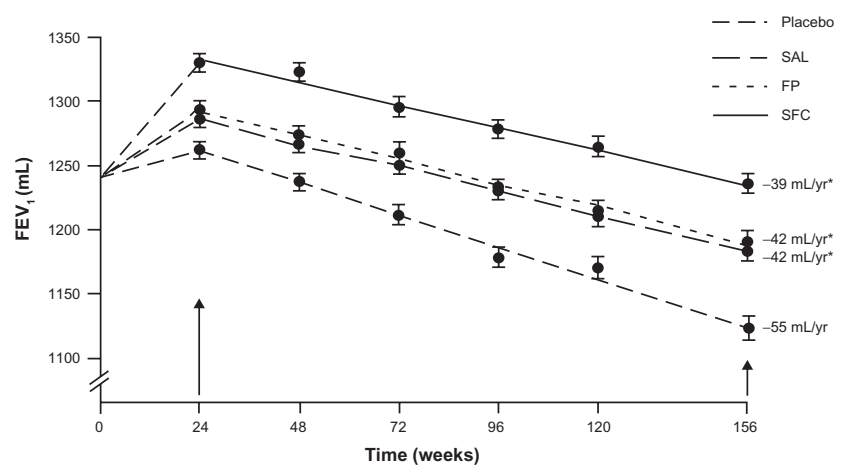

Figure 4 The decline in lung function in COPD patients treated with placebo, salmeterol (SAL), fluticasone (FP), and combination salmeterol/fluticasone (SFC). "Indicates significantly different compared to placebo. Reproduced with permission from Celli BR, Thomas NE, Anderson JA, et al. Effect of pharmacotherapy on rate of decline of lung function in chronic obstructive pulmonary disease: results from the TORCH study. Am J Respir Crit Care Med. 2008; I78(4):332-338. ${ }^{38}$ Copyright (C) 2008 American Thoracic Society.

distributed amongst the different treatment arms, introducing potential bias, with significantly more dropout in the placebo $\operatorname{arm}(18 \%$ vs $9 \%$ in the combination therapy arm). Although it could be assumed that those who dropped out had a faster rate of lung function decline, Suissa has convincingly shown how this assumption could be false, since the data could be skewed by the phenomenon of regression to the mean. ${ }^{70,71}$ Nevertheless the TORCH trial provides the first evidence that treatment of COPD can slow the accelerated decline in $\mathrm{FEV}_{1}$. Although there was a significant decrease in the number of exacerbations, even in patients who had no exacerbations during the trial there was a similar difference in the rate of decline between those on placebo ( $56 \mathrm{~mL}$ per year) and those with some form of active treatment (27 to $31 \mathrm{~mL}$ per year). Since there was improvement in both the salmeterol and fluticasone groups, but little added improvement in the combination group it suggests that there are multiple potential mechanisms for improvement in lung function. Further studies are needed to elucidate whether there may be a limit or ceiling effect on the total amount of improvement possible.

The second very large COPD treatment trial was the Understanding Potential Long-Term Impacts on Function with Tiotropium (UPLIFT) trial. ${ }^{72}$ This was also a large, multi-center, randomized, placebo-controlled trial in moderate to severe COPD patients. Tiotropium was compared to placebo with the primary outcome rate of decline in $\mathrm{FEV}_{1}$. Importantly, patients were allowed to continue respiratory medications other than an inhaled anti-cholinergic, and the majority of patients were on a long-acting beta-agonist and/or an inhaled corticosteroid. Again, about 6000 patients were recruited, with $60 \%$ completing 45 months of follow-up. The addition of tiotropium did not slow the rate of $\mathrm{FEV}_{1}$ decline compared to placebo. In this trial, the rate of decline was only $38 \mathrm{~mL}$ per year in the treatment arm, and $40 \mathrm{~mL}$ per year in the placebo arm, only slightly greater than expected due to normal aging. Possible explanations of these data are the relatively low rate of smoking (as compared to other studies), which may have a much greater effect than any medication on the rate of lung function decline, and the high rate of concurrent use of other kinds of COPD medications. In support of this latter hypothesis, there was a difference in the rate of decline in post-bronchodilator $\mathrm{FEV}_{1}$ between tiotropium and placebo in those subjects not on either an inhaled corticosteroid or long-acting beta-agonist $(40 \pm 3 \mathrm{~mL}$ per year in the tiotropium group vs $47 \pm 3 \mathrm{~mL}$ per year in the placebo group, $P=0.046$ ). Subgroup analysis of this cohort also suggested that the use of tiotropium was also associated with a slower rate of decline in the group of patients with more mild disease [GOLD stage II $\left(50 \% \leq \mathrm{FEV}_{1}<80 \%\right.$ predicted, and $\left.\left.\mathrm{FEV}_{1} / \mathrm{FVC}<70 \%\right)\right]^{73}$

Although both TORCH and UPLIFT suggest that pharmacotherapy can modestly slow the rate of lung function decline, the different types of medications studied in each trial presumably work through different pathways. Indirect evidence for this comes from the INSPIRE trial, which compared the rate of exacerbations in severe COPD using combination salmeterol/fluticasone or tiotropium. ${ }^{74}$ Although the drugs were equally efficacious at preventing exacerbations, when an exacerbation did occur, antibiotics were used more frequently in the salmeterol/fluticasone arm and steroids more often in the tiotropium arm, suggesting that the exacerbations were qualitatively different depending on the treatment arm. In clinical practice, all three types of medications are often combined, and probably offer additional benefits in terms of acute changes in $\mathrm{FEV}_{1}$, symptom scores and quality of life, but as of yet there are minimal long term data to assess the impact of this combination therapy on the rate of $\mathrm{FEV}_{1}$ decline since such trials have typically only run for 12 months or less..$^{75,76}$

To summarize: commonly used medications appear to modestly slow the accelerated decline in lung function in COPD. Inhaled corticosteroids have an anti-inflammatory effect, which presumably explains their benefit. In contrast, the mechanism by which bronchodilators slow lung function decline is unknown. When combined, the effects of different classes of medications could be additive. Given the small absolute amount of lung function benefit, any clinically meaningful preservation of lung function would likely require years of daily medication use (as well as very long 
clinical trials to detect), probably in patients with less severe COPD. The lung function preservation benefits would need to be weighed against the adverse effects and the costs of these medications. While beyond the scope of this review, several reported side effects might be important. The inhaled corticosteroids have been implicated in greater rates of osteoporosis in some, ${ }^{64}$ but not all, ${ }^{77}$ trials. In the TORCH trial (and some other trials of inhaled corticosteroids ${ }^{78}$ ), there was a higher rate of pneumonia in the treatment arms receiving high-dose fluticasone. For tiotropium specifically, there is wide disparity with regard to its reported effects on cardiovascular mortality. ${ }^{79}$

\section{Other COPD medications}

Besides the commonly used medications above, other pharmacotherapies have been tried based on pathways that might be important in COPD pathogenesis and lung function decline. Most of the work to date is preliminary or of limited applicability, but has been interesting and hypothesis generating.

\section{Anti-oxidants}

Oxidative stress is thought to play a role in COPD pathogenesis. A number of trials sought to investigate the role of antioxidant therapy on exacerbations and lung function decline. ${ }^{80}$ The recently completed BRONCUS trial was a 3-year, randomized, placebo controlled trial of $600 \mathrm{mg}$ $\mathrm{N}$-acetylcysteine and its effect on exacerbations and the rate of decline in $\mathrm{FEV}_{1}{ }^{81}$ The trial was negative for both endpoints, although subgroup analysis suggested that the therapy might reduce exacerbations in those not taking inhaled corticosteroids (perhaps similar to UPLIFT?). Another anti-oxidant, carbocisteine, was recently reported in the PEACE trial to decrease exacerbations during 1 year of active treatment compared to placebo. ${ }^{82}$ Carbocisteine also has mucolytic and anti-inflammatory properties, so the exact mechanism of any benefit is unknown. Nevertheless, anti-oxidant therapy is an area of active research for COPD treatment and exacerbation prevention. ${ }^{83}$

\section{Antibiotics}

Given the role of exacerbations in COPD pathogenesis, morbidity and mortality, many researchers have used antibiotic therapy to prevent exacerbations. As well summarized by Kunisaki and Niewoehner, there is a long history of antibiotic use in COPD, but this was mostly abandoned after relatively disappointing trials in the $1950 \mathrm{~s}$ and 1960s. ${ }^{84}$ Recently, Seemungal and colleagues revived the idea in a year-long, randomized, placebo-controlled trial of erythromycin. ${ }^{85}$ In this study, treatment with the antibiotic significantly reduced exacerbations in moderate to severe COPD. Although macrolides may have other anti-inflammatory properties ${ }^{86}$ there was no evidence of an anti-inflammatory effect; that is, the benefits seemed to accrue only due to the antimicrobial properties of the drug. No difference in lung function decline was seen in this (relatively short) 12-month trial. While such a strategy focuses on preventing exacerbations, even prompt reporting of exacerbations and rapid treatment with antibiotics could also influence lung function decline, as well as other COPD outcomes. $^{87}$

Alpha-I-antitrypsin augmentation therapy Alpha-1-antitrypsin (AAT) deficiency provides a unique model of COPD, due to the loss of a protease inhibitor in affected individuals. The protease/anti-protease imbalance can be restored by intravenous augmentation of AAT. Several non-randomized studies have shown that progression of disease can be slowed by therapy, though the effect may be modest and may not be evident for many years. ${ }^{88-90}$ While this specific therapy is not applicable to most with COPD, ${ }^{91}$ these results suggest that anti-protease therapy in general could have a role in slowing the decline in lung function.

\section{Other anti-inflammatory therapies}

Non-steroidal anti-inflammatory therapies have also been investigated. Among the most intriguing are the results from non-randomized trials looking at statin use in COPD. Statins, 3-hydroxy 3-methylglutaryl coenzyme A reductase inhibitors, are used extensively to prevent cardiovascular disease. In addition to their lipid lowering effects, it is clear that they also have anti-inflammatory properties. ${ }^{92}$ Observational trials have suggested that statins reduce mortality in COPD, a finding that may not be surprising given the risk of cardiovascular disease in this population. ${ }^{93}$ However, statins have also been reported to reduce exacerbations, and in one retrospective observational trial statin use was associated with a markedly reduced decline in FEV1. ${ }^{94}$ Because patients who use statins may be fundamentally different from those who do not, ${ }^{95}$ particularly for other medication use and habits, such results will need to be supported by randomized trials.

Phosphodiesterases (PDEs) are a family of enzymes that inactivate intracellular messengers cyclic AMP and cyclic GMP, which play important roles in the activity of many 
different cell types. PDE-4 has been of interest in COPD since this specific enzyme is found in immune and inflammatory cells as well as airway smooth muscle cells. PDE-4 inhibition can decrease airway inflammation in COPD, as assessed by sputum neutrophil and eosinophil counts. ${ }^{96}$ In addition, one small trial showed that tissue inflammation was reduced with PDE-4 inhibition, which may suggest a role for these drugs in preventing airway and parenchyma remodeling in COPD. ${ }^{97}$ Recent trials have shown that in select populations of COPD patients, the PDE-4 inhibitor roflumilast can improve lung function and reduce exacerbations when administered for 12 months. ${ }^{98,99}$ What role, if any, this class of medications has in prevention of long-term lung function decline has not yet been determined.

Other anti-inflammatory medications have been used, such as anti-TNF- $\alpha$ agents. Although a large trial was negative, ${ }^{100}$ other pathways will no doubt be targeted in the future, and perhaps in earlier stages of disease. ${ }^{101}$

\section{Patient education and patient-physician partnership}

Although only recently a focus of rigorous investigation, patient education and partnership programs between patients and healthcare providers are likely to be important in COPD management and treatment. ${ }^{102,103}$ All medications require proper administration and dosing to achieve the desired effect. Similarly, early intervention in the course of an exacerbation may be crucial. Thus, education efforts should focus on several important areas including instruction on proper use of inhaled medications (particularly those supplied via unique delivery systems), early recognition of exacerbations, and avoidance of known precipitants. Patient guides are available from several sources, including www. goldcopd.org and www.internationalcopd.org. At each visit, proper compliance with maintenance medications should be emphasized. Practitioners should strive for a partnership with their patients (and ensure that the necessary systems are in place) that would allow for rapid notification and treatment of exacerbations. Although not within the realm of pharmacotherapy, we welcome further research efforts assessing these types of interventions on the rate of lung function decline.

\section{Summary}

COPD is an inflammatory disease associated with accelerated lung function decline. Data from trials with large numbers of participants and multi-year follow-up suggest that commonly used pharmacotherapy can modestly improve the decline in lung function in COPD. Given that the benefit is small, it may be beneficial to start treatment early in the course of disease to preserve lung function over time. However, such a lung preservation strategy would need to be balanced against the potential side effects and costs associated with prolonged therapy. Alternatively, other more targeted therapies currently under investigation may offer greater benefit in the future.

\section{Disclosures}

The authors declare no conflicts of interest.

\section{References}

1. Agusti A. Systemic effects of chronic obstructive pulmonary disease: what we know and what we don't know (but should). Proc Am Thorac Soc. 2007;4(7):522-525.

2. Agusti AG, Sauleda J, Miralles C, et al. Skeletal muscle apoptosis and weight loss in chronic obstructive pulmonary disease. Am J Respir Crit Care Med. 2002;166(4):485-489.

3. Barnes PJ, Celli BR. Systemic manifestations and comorbidities of COPD. Eur Respir J. 2009;33(5):1165-1185.

4. Sin DD, Man SF. Chronic obstructive pulmonary disease as a risk factor for cardiovascular morbidity and mortality. Proc Am Thorac Soc. 2005;2(1):8-11.

5. Sin DD, Man SF. Impact of cancers and cardiovascular diseases in chronic obstructive pulmonary disease. Curr Opin Pulm Med. 2008;14(2):115-121.

6. Jemal A, Ward E, Hao Y, Thun M. Trends in the leading causes of death in the United States, 1970-2002. JAMA. 2005;294(10):1255-1259.

7. Mundy C, Kirkpatrick P. Tiotropium bromide. Nat Rev Drug Discov. 2004;3(8):643-644.

8. Jindal SK. Emergence of chronic obstructive pulmonary disease as an epidemic in India. Indian J Med Res. 2006;124(6):619-630.

9. Murray CJ, Lopez AD. Alternative projections of mortality and disability by cause 1990-2020: Global Burden of Disease Study. Lancet. 1997;349(9064):1498-1504.

10. Rabe KF, Hurd S, Anzueto A, et al. Global strategy for the diagnosis, management, and prevention of chronic obstructive pulmonary disease: GOLD executive summary. Am J Respir Crit Care Med. 2007;176(6):532-555

11. Celli BR, Cote CG, Marin JM, et al. The body-mass index, airflow obstruction, dyspnea, and exercise capacity index in chronic obstructive pulmonary disease. N Engl J Med. 2004;350(10):1005-1012.

12. Anthonisen NR, Skeans MA, Wise RA, Manfreda J, Kanner RE, Connett JE. The effects of a smoking cessation intervention on 14.5-year mortality: a randomized clinical trial. Ann Intern Med. 2005;142(4):233-239.

13. Fletcher $\mathrm{C}$, Peto $\mathrm{R}$. The natural history of chronic airflow obstruction. Br Med J. 1977;1(6077):1645-1648.

14. Janssens JP, Pache JC, Nicod LP. Physiological changes in respiratory function associated with ageing. Eur Respir J. 1999;13(1): 197-205.

15. Sharma G, Goodwin J. Effect of aging on respiratory system physiology and immunology. Clin Interv Aging. 2006;1(3):253-260.

16. Kerstjens HA, Rijcken B, Schouten JP, Postma DS. Decline of FEV1 by age and smoking status: facts, figures, and fallacies. Thorax. 1997;52(9):820-827.

17. Brandstetter RD, Kazemi H. Aging and the respiratory system. Med Clin North Am. 1983;67(2):419-431.

18. Lange P, Parner J, Vestbo J, Schnohr P, Jensen G. A 15-year follow-up study of ventilatory function in adults with asthma. $N$ Engl J Med. 1998;339(17):1194-1200. 
19. Permutt $S$, Martin HB. Static pressure-volume characteristics of lungs in normal males. J Appl Physiol. 1960;15:819-825.

20. Mittman C, Edelman NH, Norris AH, Shock NW. Relationship between chest wall and pulmonary compliance and age. J Appl Physiol. 1965 1965;20(6):1211-1216.

21. Polkey MI, Harris ML, Hughes PD, et al. The contractile properties of the elderly human diaphragm. Am J Respir Crit Care Med. 1997;155(5):1560-1564.

22. Tolep K, Higgins N, Muza S, Criner G, Kelsen SG. Comparison of diaphragm strength between healthy adult elderly and young men. Am J Respir Crit Care Med. 1995;152(2):677-682.

23. Enright PL, Kronmal RA, Manolio TA, Schenker MB, Hyatt RE. Respiratory muscle strength in the elderly. Correlates and reference values. Cardiovascular Health Study Research Group. Am J Respir Crit Care Med. 1994;149(2 Pt 1):430-438.

24. Tolep K, Kelsen SG. Effect of aging on respiratory skeletal muscles. Clin Chest Med. 1993;14(3):363-378.

25. Verbeken EK, Cauberghs M, Mertens I, Clement J, Lauweryns JM, Van de Woestijne KP. The senile lung. Comparison with normal and emphysematous lungs. 1. Structural aspects. Chest. 1992;101(3): 793-799.

26. Thurlbeck WM, Angus GE. Growth and aging of the normal human lung. Chest. 1975;67(2 Suppl):3S-6S.

27. Niewoehner DE, Kleinerman J, Liotta L. Elastic behavior of postmortem human lungs: effects of aging and mild emphysema. J Appl Physiol. Dec 1975;39(6):943-949.

28. Turner JM, Mead J, Wohl ME. Elasticity of human lungs in relation to age. J Appl Physiol. 1968;25(6):664-671.

29. Hogg JC, Chu F, Utokaparch S, et al. The nature of small-airway obstruction in chronic obstructive pulmonary disease. $N$ Engl $J$ Med. 2004;350(26):2645-2653.

30. Crapo RO, Morris AH, Clayton PD, Nixon CR. Lung volumes in healthy nonsmoking adults. Bull Eur Physiopathol Respir. 1982;18(3): 419-425.

31. Loring SH, Garcia-Jacques M, Malhotra A. Pulmonary characteristics in COPD and mechanisms of increased work of breathing. J Appl Physiol. 2009;107(1):309-314

32. Gold DR, Wang X, Wypij D, Speizer FE, Ware JH, Dockery DW. Effects of cigarette smoking on lung function in adolescent boys and girls. N Engl J Med. 1996;335(13):931-937.

33. Tager IB, Munoz A, Rosner B, Weiss ST, Carey V, Speizer FE. Effect of cigarette smoking on the pulmonary function of children and adolescents. Am Rev Respir Dis. 1985;131(5):752-759.

34. Tager IB, Segal MR, Speizer FE, Weiss ST. The natural history of forced expiratory volumes. Effect of cigarette smoking and respiratory symptoms. Am Rev Respir Dis. 1988;138(4):837-849.

35. Anthonisen NR, Connett JE, Murray RP. Smoking and lung function of Lung Health Study participants after 11 years. Am J Respir Crit Care Med. 2002;166(5):675-679.

36. Scanlon PD, Connett JE, Waller LA, Altose MD, Bailey WC, Buist AS. Smoking cessation and lung function in mild-tomoderate chronic obstructive pulmonary disease. The Lung Health Study. Am J Respir Crit Care Med. 2000;161(2 Pt 1): 381-390.

37. Hunninghake GM, Cho MH, Tesfaigzi Y, et al. MMP12, lung function, and COPD in high-risk populations. $N$ Engl $J$ Med. 2009;361(27):2599-2608.

38. Celli BR, Thomas NE, Anderson JA, et al. Effect of pharmacotherapy on rate of decline of lung function in chronic obstructive pulmonary disease: results from the TORCH study. Am J Respir Crit Care Med. 2008;178(4):332-338.

39. Lokke A, Lange P, Scharling H, Fabricius P, Vestbo J. Developing COPD: a 25 year follow up study of the general population. Thorax. 2006;61(11):935-939.

40. Godtfredsen NS, Lam TH, Hansel TT, et al. COPD-related morbidity and mortality after smoking cessation: status of the evidence. Eur Respir J. 2008;32(4):844-853.
41. Gamble E, Grootendorst DC, Hattotuwa K, et al. Airway mucosal inflammation in COPD is similar in smokers and ex-smokers: a pooled analysis. Eur Respir J. 2007;30(3):467-471.

42. Anderson D, Macnee W. Targeted treatment in COPD: a multi-system approach for a multi-system disease. Int J Chron Obstruct Pulmon Dis. 2009;4:321-335.

43. Ito K, Barnes PJ. COPD as a disease of accelerated lung aging. Chest. 2009;135(1):173-180.

44. MacNee W. Accelerated lung aging: a novel pathogenic mechanism of chronic obstructive pulmonary disease (COPD). Biochem Soc Trans. 2009;37(Pt 4):819-823.

45. Stanescu D, Sanna A, Veriter C, et al. Airways obstruction, chronic expectoration, and rapid decline of FEV1 in smokers are associated with increased levels of sputum neutrophils. Thorax. 1996;51(3):267-271.

46. Shapiro SD. Proteinases in chronic obstructive pulmonary disease. Biochem Soc Trans. 2002;30(2):98-102.

47. Patel BD, Loo WJ, Tasker AD, et al. Smoking related COPD and facial wrinkling: is there a common susceptibility? Thorax. 2006;61(7):568-571.

48. Holz O, Zuhlke I, Jaksztat E, et al. Lung fibroblasts from patients with emphysema show a reduced proliferation rate in culture. Eur Respir J. 2004;24(4):575-579.

49. MacNee W, Tuder RM. New paradigms in the pathogenesis of chronic obstructive pulmonary disease I. Proc Am Thorac Soc. 2009;6(6): $527-531$.

50. Wedzicha JA, Seemungal TA, MacCallum PK, et al. Acute exacerbations of chronic obstructive pulmonary disease are accompanied by elevations of plasma fibrinogen and serum IL-6 levels. Thromb Haemost. 2000;84(2):210-215.

51. Donaldson GC, Seemungal TA, Bhowmik A, Wedzicha JA. Relationship between exacerbation frequency and lung function decline in chronic obstructive pulmonary disease. Thorax. 2002;57(10):847-852 .

52. Kanner RE, Anthonisen NR, Connett JE. Lower respiratory illnesses promote FEV(1) decline in current smokers but not ex-smokers with mild chronic obstructive pulmonary disease: results from the lung health study. Am J Respir Crit Care Med. 2001;164(3): 358-364.

53. Soler-Cataluna JJ, Martinez-Garcia MA, Roman Sanchez P, Salcedo E, Navarro M, Ochando R. Severe acute exacerbations and mortality in patients with chronic obstructive pulmonary disease. Thorax. 2005;60(11):925-931.

54. Sykes A, Mallia P, Johnston SL. Diagnosis of pathogens in exacerbations of chronic obstructive pulmonary disease. Proc Am Thorac Soc. 2007;4(8):642-646.

55. Sethi S, Evans N, Grant BJ, Murphy TF. New strains of bacteria and exacerbations of chronic obstructive pulmonary disease. $N$ Engl J Med. 2002;347(7):465-471.

56. Sethi S, Mallia P, Johnston SL. New paradigms in the pathogenesis of chronic obstructive pulmonary disease II. Proc Am Thorac Soc. 2009;6(6):532-534.

57. Palmqvist M, Persson G, Lazer L, Rosenborg J, Larsson P, Lotvall J. Inhaled dry-powder formoterol and salmeterol in asthmatic patients: onset of action, duration of effect and potency. Eur Respir J. 1997;10(11):2484-2489

58. Celli BR. Update on the management of COPD. Chest. 2008;133(6): 1451-1462.

59. McNicholas WT, Calverley PM, Lee A, Edwards JC. Long-acting inhaled anticholinergic therapy improves sleeping oxygen saturation in COPD. Eur Respir J. 2004;23(6):825-831.

60. Johnson M, Rennard S. Alternative mechanisms for long-acting beta(2)adrenergic agonists in COPD. Chest. 2001;120(1):258-270.

61. Haag S, Matthiesen S, Juergens UR, Racke K. Muscarinic receptors mediate stimulation of collagen synthesis in human lung fibroblasts. Eur Respir J. 2008;32(3):555-562.

62. Iesato K, Tatsumi K, Saito K, et al. Tiotropium bromide attenuates respiratory syncytial virus replication in epithelial cells. Respiration. 2008;76(4):434-441. 
63. Burge PS, Calverley PM, Jones PW, Spencer S, Anderson JA, Maslen TK. Randomised, double blind, placebo controlled study of fluticasone propionate in patients with moderate to severe chronic obstructive pulmonary disease: the ISOLDE trial. $B M J$. 2000;320(7245):1297-1303.

64. Effect of inhaled triamcinolone on the decline in pulmonary function in chronic obstructive pulmonary disease. $N$ Engl $J$ Med. 2000;343(26):1902-1909.

65. Pauwels RA, Lofdahl CG, Laitinen LA, et al. Long-term treatment with inhaled budesonide in persons with mild chronic obstructive pulmonary disease who continue smoking. European Respiratory Society Study on Chronic Obstructive Pulmonary Disease. N Engl J Med. 1999;340(25):1948-1953.

66. Vestbo J, Sorensen T, Lange P, Brix A, Torre P, Viskum K. Long-term effect of inhaled budesonide in mild and moderate chronic obstructive pulmonary disease: a randomised controlled trial. Lancet. 1999;353(9167):1819-1823.

67. Highland KB, Strange C, Heffner JE. Long-term effects of inhaled corticosteroids on FEV1 in patients with chronic obstructive pulmonary disease. A meta-analysis. Ann Intern Med. 2003;138(12): 969-973.

68. Sutherland ER, Allmers H, Ayas NT, Venn AJ, Martin RJ. Inhaled corticosteroids reduce the progression of airflow limitation in chronic obstructive pulmonary disease: a meta-analysis. Thorax. 2003;58(11):937-941.

69. Calverley PM, Anderson JA, Celli B, et al. Salmeterol and fluticasone propionate and survival in chronic obstructive pulmonary disease. N Engl J Med. 2007;356(8):775-789.

70. Suissa S. Medications to modify lung function decline in chronic obstructive pulmonary disease: some hopeful signs. Am J Respir Crit Care Med. 2008;178(4):322-323.

71. Suissa S. Lung function decline in COPD trials: bias from regression to the mean. Eur Respir J. 2008;32(4):829-831.

72. Tashkin DP, Celli B, Senn S, et al. A 4-year trial of tiotropium in chronic obstructive pulmonary disease. $N$ Engl $J$ Med. 2008;359(15):1543-1554.

73. Decramer M, Celli B, Kesten S, Lystig T, Mehra S, Tashkin DP. Effect of tiotropium on outcomes in patients with moderate chronic obstructive pulmonary disease (UPLIFT): a prespecified subgroup analysis of a randomised controlled trial. Lancet. 2009;374(9696):1171-1178.

74. Wedzicha JA, Calverley PM, Seemungal TA, Hagan G, Ansari Z, Stockley RA. The prevention of chronic obstructive pulmonary disease exacerbations by salmeterol/fluticasone propionate or tiotropium bromide. Am J Respir Crit Care Med. 2008;177(1):19-26.

75. Aaron SD, Vandemheen KL, Fergusson D, et al. Tiotropium in combination with placebo, salmeterol, or fluticasone-salmeterol for treatment of chronic obstructive pulmonary disease: a randomized trial. Ann Intern Med. 2007;146(8):545-555.

76. Welte T, Miravitlles M, Hernandez P, et al. Efficacy and tolerability of budesonide/formoterol added to tiotropium in patients with chronic obstructive pulmonary disease. Am J Respir Crit Care Med. 2009;180(8):741-750.

77. Ferguson GT, Calverley PM, Anderson JA, et al. Prevalence and progression of osteoporosis in patients with COPD: results from the towards a revolution in COPD health study. Chest. 2009;136(6): 1456-1465.

78. Drummond MB, Dasenbrook EC, Pitz MW, Murphy DJ, Fan E. Inhaled corticosteroids in patients with stable chronic obstructive pulmonary disease: a systematic review and meta-analysis. JAMA 2008;300(20):2407-2416.

79. Hilleman DE, Malesker MA, Morrow LE, Schuller D. A systematic review of the cardiovascular risk of inhaled anticholinergics in patients with COPD. Int J Chron Obstruct Pulmon Dis. 2009;4:253-263.

80. Grandjean EM, Berthet P, Ruffmann R, Leuenberger P. Efficacy of oral long-term $\mathrm{N}$-acetylcysteine in chronic bronchopulmonary disease: a meta-analysis of published double-blind, placebo-controlled clinical trials. Clin Ther. 2000;22(2):209-221.
81. Decramer M, Rutten-van Molken M, Dekhuijzen PN, et al. Effects of $\mathrm{N}$-acetylcysteine on outcomes in chronic obstructive pulmonary disease (Bronchitis Randomized on NAC Cost-Utility Study, BRONCUS): a randomised placebo-controlled trial. Lancet. 2005;365(9470): $1552-1560$.

82. Zheng JP, Kang J, Huang SG, et al. Effect of carbocisteine on acute exacerbation of chronic obstructive pulmonary disease (PEACE Study): a randomised placebo-controlled study. Lancet. 2008;371(9629): 2013-2018.

83. Hansel TT, Barnes PJ. New drugs for exacerbations of chronic obstructive pulmonary disease. Lancet. 2009;374(9691):744-755.

84. Kunisaki KM, Niewoehner DE. Antibiotic prophylaxis for chronic obstructive pulmonary disease: resurrecting an old idea. Am J Respir Crit Care Med. 2008;178(11):1098-1099.

85. Seemungal TA, Wilkinson TM, Hurst JR, Perera WR, Sapsford RJ, Wedzicha JA. Long-term erythromycin therapy is associated with decreased chronic obstructive pulmonary disease exacerbations. Am J Respir Crit Care Med. 2008;178(11):1139-1147.

86. Martinez FJ, Curtis JL, Albert R. Role of macrolide therapy in chronic obstructive pulmonary disease. Int J Chron Obstruct Pulmon Dis. 2008;3(3):331-350.

87. Wilkinson TM, Donaldson GC, Hurst JR, Seemungal TA, Wedzicha JA. Early therapy improves outcomes of exacerbations of chronic obstructive pulmonary disease. Am J Respir Crit Care Med. 2004;169(12):1298-1303.

88. Survival and FEV1 decline in individuals with severe deficiency of alpha1-antitrypsin. The Alpha-1-Antitrypsin Deficiency Registry Study Group. Am J Respir Crit Care Med. 1998;158(1):49-59.

89. Dirksen A, Piitulainen E, Parr DG, et al. Exploring the role of CT densitometry: a randomised study of augmentation therapy in alpha1antitrypsin deficiency. Eur Respir J. 2009;33(6):1345-1353.

90. Seersholm N, Wencker M, Banik N, et al. Does alpha1-antitrypsin augmentation therapy slow the annual decline in FEV1 in patients with severe hereditary alpha1-antitrypsin deficiency? Wissenschaftliche Arbeitsgemeinschaft zur Therapie von Lungenerkrankungen (WATL) alpha1-AT study group. Eur Respir J. 1997;10(10):2260-2263.

91. Sandhaus RA, Turino G, Stocks J, et al. alpha1-Antitrypsin augmentation therapy for PI*MZ heterozygotes: a cautionary note. Chest. 2008;134(4):831-834.

92. Novack V, Eisinger M, Frenkel A, et al. The effects of statin therapy on inflammatory cytokines in patients with bacterial infections: a randomized double-blind placebo controlled clinical trial. Intensive Care Med. 2009;35(7):1255-1260.

93. Janda S, Park K, FitzGerald JM, Etminan M, Swiston J. Statins in COPD: a systematic review. Chest. 2009;136(3):734-743.

94. Keddissi JI, Younis WG, Chbeir EA, Daher NN, Dernaika TA, Kinasewitz GT. The use of statins and lung function in current and former smokers. Chest. 2007;132(6):1764-1771.

95. Platt AB, Kuna ST, Field SH, et al. Adherence to sleep apnea therapy and use of lipid-lowering drugs: a study of the healthy user effect. Chest. 2010;137(1):102-108.

96. Grootendorst DC, Gauw SA, Verhoosel RM, et al. Reduction in sputum neutrophil and eosinophil numbers by the PDE4 inhibitor roflumilast in patients with COPD. Thorax. 2007;62(12): 1081-1087.

97. Gamble E, Grootendorst DC, Brightling CE, et al. Antiinflammatory effects of the phosphodiesterase-4 inhibitor cilomilast (Ariflo) in chronic obstructive pulmonary disease. Am J Respir Crit Care Med. 2003;168(8):976-982.

98. Calverley PM, Rabe KF, Goehring UM, Kristiansen S, Fabbri LM, Martinez FJ. Roflumilast in symptomatic chronic obstructive pulmonary disease: two randomised clinical trials. Lancet. 2009;374(9691): 685-694.

99. Fabbri LM, Calverley PM, Izquierdo-Alonso JL, et al. Roflumilast in moderate-to-severe chronic obstructive pulmonary disease treated with longacting bronchodilators: two randomised clinical trials. Lancet. 2009;374(9691):695-703 
100. Rennard SI, Fogarty C, Kelsen S, et al. The safety and efficacy of infliximab in moderate to severe chronic obstructive pulmonary disease. Am J Respir Crit Care Med. 2007;175(9):926-934.

101. Barnes PJ. Unexpected failure of anti-tumor necrosis factor therapy in chronic obstructive pulmonary disease. Am J Respir Crit Care Med. 2007;175(9):866-867.
102. Clark NM, Dodge JA, Partridge MR, Martinez FJ. Focusing on outcomes: making the most of COPD interventions. Int $J$ Chron Obstruct Pulmon Dis. 2009;4:61-77.

103. Rasekaba TM, Williams E, Hsu-Hage B. Can a chronic disease management pulmonary rehabilitation program for COPD reduce acute rural hospital utilization? Chron Respir Dis. 2009;6(3):157-163.

\section{Publish your work in this journal}

The International Journal of COPD is an international, peer-reviewed journal of therapeutics and pharmacology focusing on concise rapid reporting of clinical studies and reviews in COPD. Special focus is given to the pathophysiological processes underlying the disease, intervention programs, patient focused education, and self management protocols.

\section{Dovepress}

This journal is indexed on PubMed Central, MedLine and CAS. The manuscript management system is completely online and includes a very quick and fair peer-review system, which is all easy to use. Visit $\mathrm{http} / / / \mathrm{www}$.dovepress.com/testimonials.php to read real quotes from published authors.

Submit your manuscript here: http://www.dovepress.com/international-journal-of-copd-journal 